\title{
The effect of administered corticosteroids on the growth of children
}

\author{
M. A. PReECE \\ M.B.B.S., M.R.C.P., D.C.H. \\ Department of Growth and Development, Institute of Child Health, University of London
}

\begin{abstract}
Summary
The growth-inhibiting effect of exogenous corticosteroids has been reported in many papers. Most of them have concerned the clinical problems of asthma and rheumatoid arthritis but it is probable that the underlying disease is relatively unimportant in determining the effect on growth. Steroid therapy on alternate days seems to produce less undesirable effects than steroid treatment every day and corticotrophin may be preferable.

Although the mechanisms are uncertain it seems likely that the action is peripheral and certainly exogenous growth hormone does not prevent the steroid effect. A minimal dosage of corticosteroids should always be used in replacement therapy for hypopituitarism.
\end{abstract}

THE harmful effects of glucocorticoids on growth are well known to all clinicians who treat children. In general, this is recognized in the management of bronchial asthma, rheumatoid arthritis and the nephrotic syndrome, as these are the most common childhood disorders that are treated with long-term corticosteroids. This poor growth may also be associated with a degree of maturational delay, which is usually observed as delayed skeletal age. The mechanism of this effect on growth and how to prevent it is not known. Investigation of the various conditions in which it occurs can, however, give us valuable insight into the pathogenesis of the poor growth and perhaps suggest ways of avoiding it.

Growth retardation has long been recognized as a feature of childhood Cushing's syndrome where the source of excessive glucocorticoids is endogenous. Prader, Tanner and von Harnack (1963) described a girl who had suffered with Cushing's syndrome from 4 months to 4 years of age, at which time an adrenal adenoma was removed. By the time of the operation she was $5 \cdot 2 \mathrm{~s}$.d. below the mean of stature for age although her weight was well above the mean. The growth velocity over the 2 years before the operation was $3.2 \mathrm{~cm} /$ year but following the surgery it increased rapidly so that it was $17.8 \mathrm{~cm} /$ year during the subsequent year. Growth velocity remained above the

Correspondence: M. A. Preece, Institute of Child Health, 30 Guilford Street, London WC1N 1EH. mean until after 11 years of age by which time her stature was well inside the normal range. Skeletal maturation was delayed by 2.7 'years' at the time of surgery but advanced very rapidly after the removal of the tumour so that at 11 years of age the bone age was some 1.5 'years' advanced.

Similar reports of the growth retarding effect and postoperative growth of Cushing's syndrome have been reported by Strickland et al. (1972) in four cases due to bilateral adrenal hyperplasia. Their cases were all older than that of Prader et al. (1963) at the time of surgery $(9 \cdot 8-15 \cdot 8$ years) but all showed similar 'catch-up' growth. In three of these cases the serum growth hormone concentration in response to insulin hypoglycaemia and arginine infusion was measured before surgery and in all four patients afterwards. In one of the cases tested before surgery, an abnormally low growth hormone response was observed. In the other two cases the response was in the normal range and in all four cases the postoperative tests gave quite normal responses.

\section{Growth in children receiving systemic steroids for chronic asthma}

In a condition such as perennial and intractable asthma, a multiplicity of factors of varying importance may influence growth. The illness itself may have important effects, but certainly nutritional and pharmacological influences may overlay and aggravate this basic problem. In recent years the role of prolonged therapy with corticosteroids in suppressing growth has attracted great interest, and ways have been sought to minimize the harmful effects or to avoid them completely. Falliers et al. (1963) reviewed the growth status in two groups of asthmatic children; one group included many who were receiving systemic steroids and were in-patients, the other group received conservative treatment only as out-patients.

There were 302 children in the first group who were considered to have intractable asthma and who were admitted to the Children's Asthma Research Institute and Hospital in Denver, U.S.A., between 1958 and 1960. The age group of the patients ranged from 5 to 16 years and they were in residence for an average of 18 months. Heights and weights were 
TABLE 1. The distribution of height in the groups of asthmatic patients admitted to the Children's Asthma Research Institute and Hospital in Denver, U.S.A., and a further 103 children seen as out-patients.

\begin{tabular}{cccccc}
\hline & $\begin{array}{c}\text { Theoretical } \\
\text { normal }\end{array}$ & \multicolumn{2}{c}{ No steroids } & & Intermittent \\
\cline { 3 - 4 } s.d. mean & population & $1940-1950$ & $1958-1960$ & $\begin{array}{c}\text { Continuous } \\
\text { steroids }\end{array}$ & steroids \\
\hline$>+2 \cdot 0$ & $2 \cdot 3$ & $1 \cdot 9$ & $0 \cdot 0$ & $1 \cdot 9$ & 0 \\
$+2 \cdot 0-+1 \cdot 0$ & $13 \cdot 6$ & $4 \cdot 9$ & $2 \cdot 0$ & $10 \cdot 1$ & $3 \cdot 2$ \\
$+1 \cdot 0-0 \cdot 0$ & $34 \cdot 1$ & $20 \cdot 4$ & $14 \cdot 3$ & $9 \cdot 5$ & $9 \cdot 5$ \\
$0 \cdot 0--1 \cdot 0$ & $34 \cdot 1$ & $33 \cdot 0$ & $46 \cdot 9$ & $32 \cdot 3$ & $25 \cdot 3$ \\
$-1 \cdot 0-2 \cdot 0$ & $13 \cdot 6$ & $31 \cdot 1$ & $28 \cdot 6$ & $31 \cdot 0$ & $29 \cdot 5$ \\
$>-2 \cdot 0$ & $2 \cdot 3$ & $8 \cdot 7$ & $8 \cdot 2$ & $15 \cdot 2$ & $32 \cdot 6$ \\
Total no. & - & 103 & 49 & 158 & 95 \\
\hline
\end{tabular}

determined on admission and at regular intervals thereafter, and these measurements were compared with standards for an equivalent normal population. Initially, $20 \%$ of the children were 2 or more s.d. below the mean for height, which is about ten times as many as would be expected in the general population.

Bone age was also determined on admission and at yearly intervals during their stay, using the method of Greulich and Pyle (1959), and in general there was an equivalent degree of maturational delay; that is, the children on average had a normal height for bone age, although a low height for chronological age. Thus, at least part of the short stature was due to growth retardation.

Retrospective histories of the patients' intake of steroids were recorded as far as possible and allowed the division of these 302 children into three subgroups as shown in Table 1. The three sub-groups were: (a) children who had never received steroids $(16.2 \%)$; (b) children who had received interrupted courses of steroids $(52.3 \%)$; (c) children who had received steroids continuously or with only short interruptions for at least 1 year before admission $(31.5 \%)$.

In the majority of children in the category (c) there was a long history of steroid administration which had usually started intermittently and gradually become continuous. Also shown is the height distribution for a second major group, consisting of 103 children seen on a purely out-patient basis between 1940 and 1950 . None had received steroids and their asthma was probably milder.

Comparison of the children's stature with their history of steroid dosage indicated that the children with more normal growth had on the whole received less steroids. For example, only about $8 \%$ of the children who had received no steroids in the past were more than 2 s.d. below the mean for stature whereas $33 \%$ of the children on continuous steroids were below this same limit. Recalculations from the published data show that the proportion of children with heights more than 2 s.d. below the mean dif $\frac{3}{5}$. fered very significantly between the groups, being lower in those with low or absent dosage $(P<0.005) \frac{\Omega}{N}$ The more steroids, the shorter the child.

A major problem with this type of datum is the interaction between the severity of the disease, theo steroid therapy and the effects on growth. It is almost impossible to dissociate these factors, as the more severely asthmatic patients are more likely to receive? steroids, and are also the smallest. When the statureso of the 302 children with severe asthma were com- pared with those of the 103 children treated in 1 ife pre-steroid era it was seen that the second groupo assumed an intermediate position between nornaib children and the severely affected children, many. whom had received steroids.

In the same paper the relative stunting effects of prednisone, betamethasone and cortisone were com- 0 pared. The authors came to the conclusion that dosage of prednisone of $6 \mathrm{mg} / \mathrm{m}^{2} /$ day and beta-o methasone at $0.6 \mathrm{mg} / \mathrm{m}^{2}$ would produce significant growth retarding effects but that cortisone at a dosage between 50 and $70 \mathrm{mg} / \mathrm{m}^{2} /$ day did not usually pro duce poor growth. This result is surprisingly high and does not relate well to other estimates (see below): In a more recent paper Kerrbijn and De Kroon (1968). studied seventeen children between 5.6 and 10.5 years of age (bone ages between 6.3 and 10.0 'years') These children were all treated with prednisone oro prednisolone in varying doses; each child received several different dosages of the drug for a period of at least 6 months each. Growth rates and skeleta maturation rates were related to the dosage of steroids for each child so that each acted as his own control. The authors concluded that when the dosage्c of prednisone was less than $2.9 \mathrm{mg} / \mathrm{m}^{2} /$ day there was no significant growth retardation, but when if was $>4 \mathrm{mg} / \mathrm{m}^{2} /$ day then significant growth retardation resulted. This is of particular interest, as thes former dosage level is equivalent to less than $12 \mathrm{mg}$ of cortisol $/ \mathrm{m}^{2} /$ day and therefore less than the normab daily hydrocortisone production by the adrenal gland 
whereas the higher dosage range is clearly above the normal secretion rate (Weitzman et al., 1971). These authors also showed that the higher doses of steroids were associated with a reduced rate of skeletal maturation.

The importance of the frequency of administration of exogenous steroids has been particularly investigated by Morris (1975) in a study of 189 children with severe asthma who were admitted to a residential treatment centre in Denver, U.S.A. These children were divided into two groups; ninety-one admitted in 1965 and ninety-eight in 1970. Morris concluded that significant growth and maturational delay were related to the more continuous higher dose steroid regimes whereas low frequency intermittent regimes seemed to be associated with relatively little effect. A sub-group of seventy-six children was studied while under treatment in the centre. In those where the regime was unchanged from that which the child experienced before admission, there was little effect on growth or maturational pattern. In contrast, when relatively intermittent treatment before admission was changed to a steroid-free regime, there was an increase in growth rate in all of ten such patients. The reverse was seen in two further groups of patients where steroids were increased from rare or intermittent dosage regimes to more frequent therapy. In these two situations there was a worsening in the growth retardation in eight of ten and nine of eleven cases respectively. Changes in the rate of bone age maturation paralleled the effects on linear growth.

Two major approaches have been made towards circumventing this undesirable effect of steroids. A trial of corticotrophin (ACTH) suggested that it may not only prevent the growth retardation, if used instead of corticosteroids, but that it may also reverse pre-existent growth retardation (Friedman and Strang, 1966). However, when a similar study was carried out by Norman and Sanders (1969) they failed to confirm this effect. Comparison between the two studies is not really possible, however, because the dosages of steroids and corticotrophin were different and, as Norman and Sanders (1969) state, the severity of the asthma in the two groups may have been quite different. Further, the latter paper only covered a growth period of 6 months following the first administration of the corticotrophin and this may have been an inadequate time. Zutshi, Friedman and Ansell (1971), discussing children and rheumatoid arthritis, commented that an increase in height was only observed when endogenous ACTH production had recovered, a process which may take up to 1 year.

Another regime for avoiding growth retardation has been the use of alternate-day steroid therapy. This was introduced following observations that a
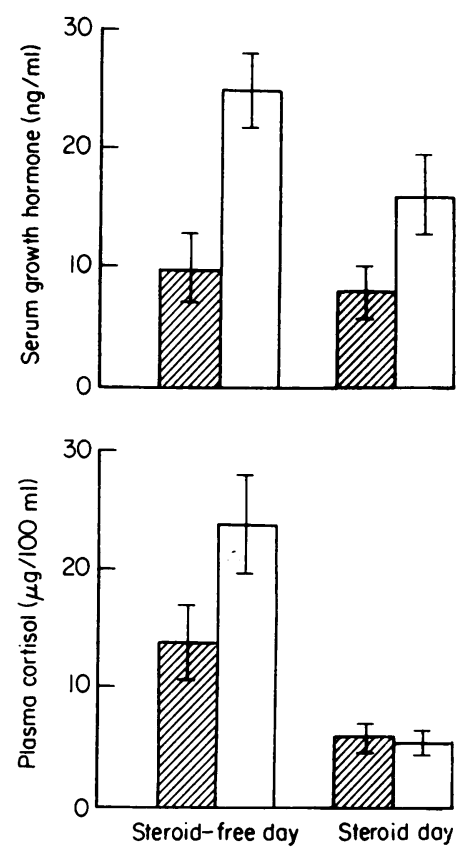

FIG. 1. Growth and hormone cortisol, fasting (ש/A) and peak during an insulin tolerance test $(\square)$; mean concentration \pm s.e. mean $(n=14)$. Data from SadeghiNejad and Senior (1969).

single dose of steroids may exert its therapeutic effect longer than its adrenal suppression effect (Reichling and Kligman, 1961). The more physiological nature of episodic doses of cortisol has also been suggested by the data of Weitzman et al. (1971) which demonstrated the pulsatile nature of cortisol secretion by the normal adrenal. Sadeghi-Nejad and Senior (1969) reported a study in fourteen children of whom seven were suffering with nephrotic syndrome, six with ulcerative colitis and one with asthma. All received alternate-day prednisone therapy for periods between 6 and 50 months. None of them showed a Cushingoid appearance and growth was normal or accelerated in twelve of the fourteen children. Insulin tolerance tests were performed on all the children on days when they were taking steroids and on days when they were not; these results are summarized in Fig. 1. On the day of prednisone ingestion the initial concentration of plasma cortisol was initially very low and failed to increase with the stress of hypoglycaemia, whereas on the steroid-free day the inital concentration of cortisol was higher and there was a marked increase in response to hypoglycaemia. The basal concentration of growth hormone was the same on the two days and on both occasions increased significantly following hypoglycaemia. However, the maximal increase of growth hormone on the steroid day was 
significantly less than that on the steroid-free day. In a rather different group of children who had renal transplantation, alternate-day steroid therapy was similarly shown to be more compatible with normal growth than daily therapy (McEnery et al., 1973). There is thus evidence that an alternate-day regime may well be preferable to continuous steroids in avoiding the harmful effects of growth, but still allow the full therapeutic benefit.

\section{Juvenile rheumatoid arthritis}

Before turning to discussion of the cause of the growth retardation in steroid treatment we should consider briefly one other cause for children to receive long-term steroids. In juvenile rheumatoid arthritis, when more conservative methods have failed, steroids or ACTH remain the only useful therapy. Here again, like asthma, growth retardation can be a problem but unlike asthma there is another problem of interpretation, namely, the destruction of many of the ossification centres by the primary disease, making assessment of skeletal maturity impossible. Retardation of growth may occur in this disease as a result of the disease process itself, particularly when the inflammatory process remains active for many years but this retardation may be intensified by maintained, long-term, daily corticosteroid therapy (Bywaters, 1965). In 1971, Zutshi et al. reported the use of ACTH therapy and concluded that if the ACTH was substituted for preexisting steroid therapy then there was some benefit in terms of growth rate in three of five patients but that there might be a flare-up of the rheumatoid process during the change-over. In contrast, if ACTH was used as the primary therapy then normal growth was usually maintained and the symptoms could, in general, be adequately controlled. Sometimes, extra therapy was needed intermittently to control acute exacerbations. These authors felt that the ACTH dosage should aim to allow endogenous ACTH production to occur, as gauged by measuring the 9 a.m. plasma cortisol levels $48 \mathrm{hr}$ after ACTH administration.

Sturge et al. (1970) studied cortisol and growth hormone secretion together with growth in another group of twenty children suffering with rheumatoid arthritis who were on four different treatment regimes. Five were receiving no steroids and they grew normally. Six were on daily steroids, three received alternate day steroids and six were receiving alternate day ACTH injections. The growth rate was least in group 2 but essentially normal in those members of groups 3 and 4 who had started on alternate steroids rather than being converted from a daily regime.

The responses of growth hormone concentration in an insulin tolerance test were inconsistent but it was concluded that they were probably normal. More recently, Daly et al. (1974) measured growth hormone, ACTH and corticosteroid concentrations during insulin tolerance tests in three different groups of patients with rheumatoid arthritis (twelve in each group); these patients were all adults. One group was receiving corticosteroids, one ACTH and the third group neither drug. It was shown that cortisol production was essentially normal in the ACTH group but very low in the steroid group; the ACTH peak was low in the ACTH group but the total amount secreted during the test (integrated response) was normal. In contrast the peak and integrated secretions were low in the steroid-treated group. The growth hormone peaks were low in both treatment groups but lower in the steroid group. They concluded that the timing of the dosage may be important; it seemed that if the steroids were given in a single large dose, there was less interference with the endogenous mechanisms. This observation accords well with the other observations which have been made about relative benefits of alternate-day steroids over the daily dosages.

\section{Mechanism of growth retardation}

The manner in which corticosteroids reduce growth is unknown. There are, however, some indio cators worth reviewing. As described above, the evidence as to the effect of steroids on growth hote mone secretion, is contradictory. It seems that the major effect is to block growth hormone action; a direct effect to inhibit its production by the pituitary is slight or non-existent. The use of exogenous growth hormone to counteract the steroid effect has been uniformly disappointing as long as the steroids have continued to be taken. Tanner et al. (1971) reported the use of human growth hormone in two children with rheumatoid arthritis who were receiving corticosteroids. In the first case there was no response, even to $60 \mathrm{i}$.u./week, while on a steroid dosage equivalent to $50 \mathrm{mg}$ of cortisone daily. In the second case, a growth spurt occurred while the patient was still receiving prednisone $3 \mathrm{mg} /$ day, but as she entered puberty at the same time the significance is obscured.

Morris et al. (1968) in short term metabolic studies $\frac{7}{2}$ and longer term growth studies showed marked impairment of the action of growth hormone in N eight steroid-treated children as compared to nonsteroid-treated children.

In patients with multiple pituitary hormone deficiencies who are receiving both steroids and growth 2 hormone replacement therapy the growth benefit of $\stackrel{O}{C}$ the latter is severely impaired by steroids, even in doses of $25 \mathrm{mg}$ cortisone acetate daily, and more markedly with larger doses. Fig. 2 shows an example of such a patient (S.J.). Clearly the full growth effect 


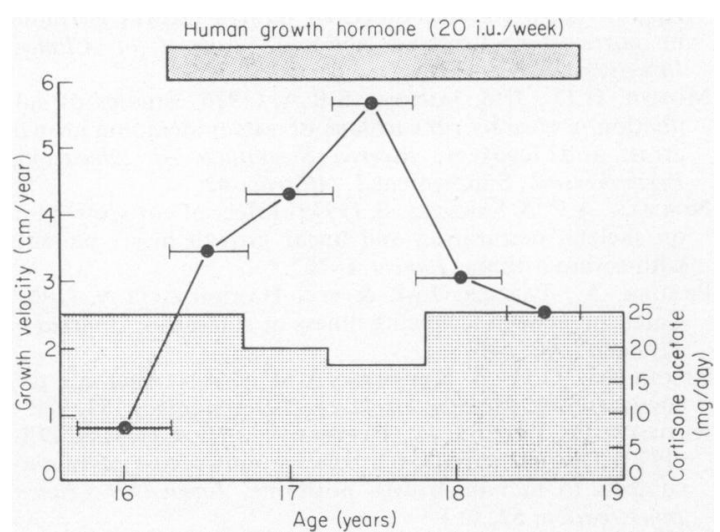

FIG. 2. Growth velocity response of patient S.J. to human growth hormone replacement while receiving different doses of cortisone acetate.

of the growth hormone was not seen until the cortisone acetate was reduced to $17.5 \mathrm{mg} /$ day and possibly further benefit would have been achieved if the dose of the steroids could have been further reduced. In a patient not receiving steroids, the maximum growth velocity on receiving growth hormone replacement is always seen in the first 3 or 6 months and the gradual build up of the growth velocity as seen in this boy is distinctly unusual. It is likely that he had been positively held back by the corticosteroids until the dosage was adequately reduced. In this context it is particularly interesting that his growth velocity was closely correlated with the dose of cortisone $(r=0.93, P<0.001)$ over six observations. Hall and Olin (1972), in hypopituitary patients receiving growth hormone and cortisol acetate found no significant growth inhibition by the latter at doses of $10-15 \mathrm{mg} / \mathrm{day}$. These results are in good agreement with our own experience in the Growth Clinic at the Hospital for Sick Children, Great Ormond Street, London.

It appears, then, that the site of action of the steroids is at the periphery. It is now well known that growth hormone induces the synthesis of a family of smaller peptides by the liver. These are usually referred to as the 'somatomedins' or 'sulphation factor' and appear to mediate the growth promoting action of growth hormone. It is therefore possible that one site of action of cortisol is in inhibiting the production of the somatomedin by the liver. In a small series of seven growth-hormonedeficient patients, Hall (1971) measured serum somatomedin concentrations following intravenous human growth injection ( 4 or 8 i.u.). All the patients were receiving maintenance growth hormone replacement and three were also receiving cortisone acetate $12.5-25 \mathrm{mg} /$ day. Maximum somatomedin response was seen at $3 \mathrm{hr}$, but no later values were reported.
In two of the three patients receiving cortisone acetate there was no somatomedin response and a similar lack of response was seen in one of the four patients not taking steroids. These data may lend some support to the supposition that the steroids inhibit the action of growth hormone on the liver. There is also evidence of interference at one of the target cells of the somatomedins, namely, the chondrocytes. The primary action of somatomedin on the chondrocyte is to stimulate the incorporation of sulphate into the cartilage molecule; Mosier and Jansons (1975) have demonstrated reduced sulphate uptake by the cartilage when exposed to corticosteroids. Similarly Van den Brande (1975) has observed a sulphate uptake inhibiting effect of high concentrations of corticosteroids in serum samples, in which somatomedin activity is being assayed by the porcine rib cartilage assay. Thus, corticosteroids in the blood samples may lower the sulphate uptake and give a falsely low value for circulating somatomedin concentrations. Clearly, much work remains to be done in this area to elucidate the actual processes involved.

\section{Conclusion}

The action of corticosteroids in inhibiting growth cannot be disputed. The mechanisms are, for the present, obscure but it appears that the action is peripheral and is reduced by alternate-day regimes. If steroids need to be used for anti-inflammatory purposes, in relatively high non-physiological doses then it seems that alternate day (or even less frequent) regimes are worthwhile. Here the dosage is dictated by the clinical response of the patients but obviously should be the minimum that will control the patient's primary symptoms.

When steroids, usually as cortisone acetate or cortisol, are being used for replacement therapy, the required dosage is much lower. In congenital adrenal hyperplasia a dosage of cortisol of $25 \mathrm{mg} / \mathrm{m}^{2}$ of body surface area has been advocated for replacement (Brook et al., 1974) but it should be remembered that this is a quite different clinical situation. In our experience of patients receiving growth hormone and cortisone acetate for hypopituitarism, doses of 7.5-10 mg of the latter have usually been adequate, provided the patient is aware of the need for increasing this at times of concurrent illnesses. The time relationships between the administration of cortisol and growth hormone has been studied by Rudman et al. (1973) studying short-term anabolic effects. It appears that if these two hormones must be given then they should be separated in time as much as possible, although no direct study has yet been made in terms of long-term growth. It would seem most physiological if the cortisol was given in the morning and growth hormone at night. 
Finally, the need for keeping the use of corticosteroids to a minimum makes especially important clear confirmation that steroid therapy is necessary, by unequivocal demonstration that ACTH secretion is impaired in hypopituitary patients.

\section{References}

Brook, C.G.D., Zachman, M., Prader, A. \& Murset, G. (1974) Experience with long-term therapy in congenital adrenal hyperplasia. Journal of Pediatrics, 85, 12.

BYWATERS, E.G.L. (1965) The present status of steroid treatment in rheumatoid arthritis. Proceedings of the Royal Society of Medicine, 58, 649.

Daly, J.R., Fletcher, M.R., Glass, D., Chambers, D.J., BITENSKY, L. \& CHAYEN, J. (1974) Comparison of effects of long-term corticotrophin and corticosteroid treatment on responses of plasma growth hormone, ACTH, and corticosteroid to hypoglycaemia. British Medical Journal, 3, 521.

Falliers, C.J., Tan, L.S., Szentivanyi, J., Jorgensen, J.R. \& Bukantz, S.C. (1963) Childhood asthma and steroid therapy as influences on growth. American Journal of Diseases of Children, 105, 127.

Friedman, M. \& Strang, L.B. (1966) Effects of long-term corticosteroids and corticotrophin on the growth of children. Lancet, ii, 568.

Greulich, W.W. \& Pyle, S.I. (1959) Radiographic Atlas of Skeletal Development of the Hand and Wrist, second edition. Stanford University Press, California.

HALL, K. (1971) Effect of administration of human growth hormone on sulphation factor activity in serum of hypopituitary patients. Acta endocrinologica, 66, 491 .

Hall, K. \& Olin, P. (1972) Sulphation factor activity and growth rate during long-term treatment of patients with pituitary dwarfism with human growth hormone. Acta endocrinologica, 69, 417.

KERREBIJN, K.F. \& KROON, J.P.M. (1968) Effect on height of corticosteroid therapy in asthmatic children. Archives of Disease in Childhood, 43, 556.

McEnery, P.T., Gonzalez, L.L., Martin, L.W. \& West, C.D. (1973) Growth and development of children with renal transplants. Use of alternate day steroid therapy. Journal of Pediatrics, 83, 806.

MORRIS, H.G. (1975) Growth and skeletal maturation in asthmatic children: effect of corticosteroid treatment. Pediatric Research, 9, 579.

Morris, H.G., Jorgensen, J.R., Elrick, H. \& Goldsmith,
R.E. (1968) Metabolic effects of human growth hormone in corticosteroid-treated children. Journal of Clinical Investigation, 47, 436.

Mosier, H.D., Jr \& JANSons, S.R.A. (1975) Studies of sulphation in vitro by rib cartilage of rats undergoing growth arrest and recovery. Ricerca Scientifica ed Educazione Permanente 2, Supplement 1, Abstract 42.

Norman, A.P. \& SANDFrs, S. (1979) Effect of corticotrophin on skeletal maturation and linear growth in six patients with severe asthma. Lancet, i, 287.

Prader, A., Tanner, J.M. \& von Harnack, G.A. (1963) Catch-up growth following illness or starvation. Journal of Pediatrics, 62, 646.

Reichling, G.H. \& Kligman, A.M. (1961) Alternate-day corticosteroid therapy. Archives of Dermatology, 83, 980.

Rudman, D., Freides, D., Patterson, J.H. \& Gibbas, D.L. (1973) Diurnal variation in the responsiveness of human subjects to human growth hormone. Journal of Clinical Investigation, 52, 912.

Sadeghi-Nejad, A. \& Senior, B. (1969) Adrenal function, growth, and insulin in patients treated with corticoids on alternate days. Pediatrics, 43, 277.

Strickland, A.L., Underwood, L.E., Voina, S.J., French, F.S. \& VAN WYK, J.J. (1972) Growth retardation in Cushing's syndrome. American Journal of Diseases of Children, 123, 207.

Sturge, R.A., Beardwell, C., Hartog, M., Wright, D. \& ANSELl, B.M. (1970) Cortisol and growth secretion in relation to linear growth: Patients with Still's disease on different therapeutic regimes. British Medical Journal, 3, 547.

Tanner, J.M., Whitehouse, R.H., Hughes, P.C.R. \& Vince, F.P. (1971) Effects of human growth hormone treatment for 1 to 7 years on growth of 100 children, with growth hormone deficiency, low birthweight, inherited smallness, Turner's syndrome, and other complaints. Archives of Disease in Childhood, 46, 745.

VAN DEN BRANDE, J.L. (1975) Plasma somatomedin activity in clinical conditions, Ricerca Scientifica ed Educazione Permanente 2, Supplement 1, Abstract 82.

Weitzman, E.D., Fukushima, D., Nogeire, C., Roffwarg, H., Gallagher, T.F. \& Hellman, L. (1971) Twenty-fourhour pattern of the episodic secretion of cortisol in normal subjects. Journal of Clinical Endocrinology and Metabolism, 33, 14.

Zutshi, D.M., Friedman, M. \& Ansell, B.M. (1971) Corticotrophin therapy in juvenile chronic polyarthritis (Still's disease) and effect on growth. Archives of Disease in Childhood, 46, 584. 